\title{
E Se a Cidade Fosse Nossa: A Educação Popular Contribui na
}

\section{Emancipação e na Humanização das Juventudes na Cidade?}

\author{
Y Si La Ciudad Fue Nuestra: La Educación Popular Contribuyen Em La
}

Emancipación Y La Humanización de la Juventude En La Ciudad?

And If the City Was Our Town: Does Popular Education Contribute to the

Emancipation and Humanization of Youth in the City?

\author{
Samuel Crissandro Tavares Ferreira ${ }^{1}$ \\ Vania Alves Martins Chaigar ${ }^{2}$
}

\begin{abstract}
Resumo
O presente texto está diretamente conectado com o meu trabalho como educador e coordenador dentro de um coletivo que é o PAIDÉIA, curso de Educação Popular ligado ao programa PAIETS/FURG, e com o meu trabalho como pesquisador à nível de mestrado em Educação no PPGEDU-FURG, dentro de um outro coletivo que é o RECIDADE - Rede de estéticas, culturas e formação da/na cidade, linha de pesquisa do Grupo de Pesquisa e Extensão Educação e Memória (FURG; CNPq). Nesse viés, a pesquisa que ainda está em andamento, se fundamenta na concepção teórica marxista e crítica para problematizar as categorias emancipação e humanização no PAIDÉIA. Convicto que a Educação Popular possui uma vertente reflexiva, crítica e contestadora, entendo que a mesma pode auxiliar na construção de perspectivas epistemológicas e práticas de luta, de resistência e de libertação, pelo viés da Pedagogia do Oprimido, aonde Paulo Freire aponta uma educação com e não para, entendendo que aqueles e aquelas que compreendem o processo educacional transformador, possuem a capacidade dialógica de construir a humanização, e como sujeitos históricos e políticos, o Ser Mais. Do mesmo modo, a emancipação em Karl Marx, está para a derrubada das relações de subserviência que a lógica do capital impõe para as mulheres e homens de nossa sociedade. Por isso, essa pesquisa está incumbida de investigar essas relações propostas pela Educação Popular (localizadas no PAIDÉIA) das Juventudes (Juventude que é diversa em classe, raça e gênero) na Cidade (Espaço de sociabilidade, subalternização, disputas, conflitos e etc.).
\end{abstract}

Palavras-Chave: Cidade,Emancipação, Educação Popular, Humanização, Juventudes.

\section{Resumen}

El presente texto está directamente conectado con mi trabajo como educador y coordinador dentro de un colectivo que es el PAIDÉIA, curso de Educación Popular ligado al programa PAIETS / FURG, y con mi trabajo como investigador a nivel de maestría en Educación en el PPGEDU-FURG, dentro de otro colectivo que es el RECURSO - Red de estéticas, culturas y formación de la ciudad, línea de investigación del Grupo de Investigación y Extensión Educación y Memoria (FURG, CNPq). En ese sesgo, la investigación que aún está en marcha, se fundamenta en la concepción teórica marxista y crítica para problematizar las categorías emancipación y humanización en el PAIDÉIA. En el caso de la educación popular, la educación popular tiene una vertiente reflexiva, crítica y contestadora, entiendo que la misma puede auxiliar en la construcción de perspectivas epistemológicas y prácticas de lucha, de resistencia y de liberación, por el sesgo de la Pedagogía del Oprimido, donde Paulo Freire apunta una educación con y no para, entendiendo que aquellos y aquellas que comprenden el proceso educacional transformador, poseen la capacidad dialógica de construir la

\footnotetext{
1 Mestrando em Educação PPGEDU-FURG; Universidade Federal do Rio Grande; Bolsista Capes; Grupo/RECIDADE; Rio Grande, Rio Grande do Sul, Brasil; apocalipse5-5 @ hotmail.com.

${ }^{2}$ Doutora em Educação pela UNISINOS e Pós-Doutorado pela PUC-RS; Professora da Universidade Federal do Rio Grande; Rio Grande, Rio Grande do Sul; vcchaigar@gmail.com.
} 
humanización, y como sujetos históricos y políticos, el Ser Más. De la misma manera, la emancipación en Karl Marx, está hacia el derrocamiento de las relaciones de subordinación que la lógica del capital impone para las mujeres y hombres de nuestra sociedad. Por eso, esta investigación está encargada de investigar esas relaciones propuestas por la Educación Popular (ubicadas en PAIDA) de las Juventudes (Juventud que es diversa en clase, raza y género) en la Ciudad (Espacio de sociabilidad, subalternización, disputas, conflictos y etc.).

Palabras clave: Ciudad, Emancipación, Educación Popular, Humanización.

\begin{abstract}
The present text is directly connected with my work as educator and coordinator within a collective that is the PAIDÉIA, Popular Education course linked to the PAIETS / FURG program, and with my work as a researcher at the Masters level in Education at PPGEDU-FURG, within another collective that is the RECIT - Network of aesthetics, cultures and formation of the city, research line of the Group of Research and Extension Education and Memory (FURG, CNPq). In this bias, the research that is still under way, is based on the Marxist and critical theoretical conception to problematize the emancipation and humanization categories in PAIDÉIA. I believe that Popular Education has a reflexive, critical and contentious side, and I understand that it can help in the construction of epistemological perspectives and practices of struggle, resistance and liberation, through the Pedagogia do Oprimido bias, where Paulo Freire points out an education with and not to, understanding that those who understand the transformative educational process have the dialogical capacity to construct humanization, and as historical and political subjects, Being More. Likewise, emancipation in Karl Marx is for the overthrow of the relations of subservience which the logic of capital imposes on the women and men of our society. Therefore, this research is in charge of investigating these relations proposed by the Popular Education (located in the PAIDÉIA) of Youths (Youth that is diverse in class, race and gender) in the City (Area of sociability, subalternization, disputes, conflicts and etc.).
\end{abstract}

Keywords: City, Emancipation, Popular Education, Humanization, Youth.

\title{
1. Introdução
}

É preciso ressaltar e sublinhar que a atual investigação se faz no espaço de educação popular Paidéia, que se desenvolve através de um preparatório para o ENEM (e antigamente vestibular), vulgarmente chamado "cursinho". Nesse espaço, como mencionei anteriormente, participo e contribuo como educador de História e algumas outras discussões do campo das ciências humanas. O cursinho PAIDEIA foi criado no ano de 2002, com o nome de Curso Pré-Vestibular Utopia, assumindo assim a identidade do PAIDEIA somente quatro anos após a sua criação. Este curso faz parte de um projeto de extensão da Universidade Federal do Rio Grande denominado PAIETS (Programa de Auxílio ao Ingresso nos Ensinos Técnico e Superior). O PAIETS apresenta inúmeros projetos voltados a comunidade como cursos de EJA, supletivos de ensino fundamental e médio e os cursinhos preparatórios pré-ENEM Nesta ótica, o PAIDEIA inclui-se no grupo dos cursinhos preparatórios pré-ENEM, assim como os demais: FENIX, Ousadia Popular, Maxximus e outros. Cada um desses cursos possui a sua particularidade e identidade, sendo que alguns deles funcionam em espaços cedidos por escolas na cidade de Rio Grande.

O curso Paidéia está localizado na cidade de Rio Grande, com suas instalações fixas, nos últimos anos, na ala acadêmica do Hospital Universitário Miguel Riet Corrêa Jr., na região central da cidade, porém, conta com a participação de inúmeros sujeitos de diferentes 
bairros da cidade (por exemplo, por mais que exista cursos de educação popular do PAIETS no bairro da Vila da Quinta, para os moradores deste mesmo bairro e que se deslocam até o centro para trabalhar, estudar e para fazer outras atividades, é melhor no ponto de vista do deslocamento, participarem do Paidéia no centro e depois retornarem para casa).O Paidéia foi criado em 2002 e inicialmente foi batizado como Pré Vestibular Utopia, porém após alguns anos, no ano de 2006, com uma reestruturação do curso o mesmo foi rebatizado como Grupo de Estudos Paidéia e quando se uniu aos demais cursos que integram o Programa de Auxílio ao Ingresso nos Ensinos Técnico e Superior - PAIETS seu nome foi reduzido apenas para Paidéia.

Nesse ínterim, aproveito para ressaltar que uma das minhas hipóteses na minha caminhada no Paidéia e nessa pesquisa, é o entendimento que esse espaço é sim um espaço onde protagonismos se encontram e se potencializam, ao mesmo tempo em que protagonismos são formados e entendidos como tal. Digo isto com base nas vivências cotidianas, na constatação de que pessoas se entenderam como educadoras nesse espaço, constituindo experiências e vivendo à docência e o contato com o Paidéia, e isso foi significativo.

O primeiro objetivo do Paidéia não é a entrada na universidade, mesmo entendendo que a universidade é sim, um espaço de luta e ainda constituído como espaço de legitimação dentro de nossa sociedade. Esse talvez seja o segundo objetivo. Por isso, entendemos que antes disso, é necessário um processo de criticidade, de reflexão e de leitura de mundo, para que nesse viés, essas pessoas (no caso da pesquisa, as juventudes) construam posturas críticas, estando na universidade futuramente ou não. Por isso, o primeiro objetivo é da reafirmação da educação popular na construção de saberes e conhecimentos que nos façam entender a realidade em que vivemos, desnaturalizando o que parece natural, desmitificando o que é tido como sagrado e caminhando contraponto contra qualquer esperança ingênua.

Entendo que emancipação e humanização são conceitos que possuem um peso epistemológico, ontológico, gnosiológico e histórico em relação a todo esse processo que estamos vivenciando, esse processo de aumento das desigualdades, de desconstituição de democracias, desvalorização e precarização da educação e entre outras coisas. E por isso, investigarmos a relação entre a educação popular, cidade e juventudes, poderá nos fazer entender as relações, os movimentos e construções na perspectiva da emancipação e da humanização. 


\section{Metodologia.}

Nesse capítulo, para além do desenvolvimento das categorias a serem investigadas, métodos de coleta de dados, métodos de análise de dados, dos princípios desses métodos, ferramentas e outros utensílios que comporão o realizar da pesquisa, cabe esclarecer que essa investigação que está sendo construída, está baseada em relações sociais estabelecidas a partir de relações educacionais e principalmente, na relação responsável e solidária de trocas com sujeitos sociais e reais. Por isso, essa pesquisa não é mais ou menos importante do que qualquer outra, porém se faz necessária pelo fato de que tenta se aproximar da melhor forma possível do entendimento sobre a construção emancipatória de homens e mulheres. Por mais que a pesquisa se dê e se desenvolva a partir de um espaço de educação popular, que como hipótese penso que seja uma perspectiva que possibilite emancipação e humanização, tentando compreender as articulações das juventudes na cidade, em tempos onde ainda a educação se refaz em um esforço cotidiano e contínuo de posturas de reafirmações (falo aqui das lutas pela educação, dos seus espaços, dos e das profissionais em educação), a pesquisa em educação e na educação em nenhum momento se coloca em posição de inferioridade ou em alguma categoria secundária em relação a outras áreas do conhecimento, mas pelo contrário, é extremamente imprescindível para o desvendar de nossa realidade política, social, cultural, econômica e ambiental. É necessário pesquisar e investigar com esses sujeitos, principalmente pelo fato de que esses mesmos, trazem em suas vidas as experiências que potencializam a educação popular ao mesmo tempo em que coletivamente, também podem construir de modo mais contundente, a emancipação.

Mais do que em todas as épocas anteriores, nesta época de nosso tempo, pensada como a "era do conhecimento" ou a "era da consciência", o lugar da educação é tão nuclear e crucial quanto o da ciência. Mais do que nunca, seremos o que fizermos conosco e entre nós, por meio da educação que nos forma...Ou conforma. Assim, podemos pensar em que razão de ser educação não é apenas o ato de capacitar instrumentalmente produtores humanos, por meio da transferência de conhecimentos consagrados e em nome de habilidades aproveitáveis. Antes disso, e muito além disso, ela é o gesto de formar pessoas na inteireza de seu ser e de sua vocação de criarem-se a si mesmas e partilharem com os outros a construção livre e responsável de seu próprio mundo social da vida cotidiana. (BRANDÃO, 2003, p. 20-21)

É nesse ambiente e nesse espaço em que a pesquisa se configura, no tentar entender, a partir da pesquisa, como a educação popular (nesse caso o curso Paidéia) contribui para a construção da emancipação e da humanização, categorias imprescindíveis para o cumprimento da vocação ontológica dos homens e das mulheres. Por isso, no entendimento que a educação é e deve ser política, crítica e reflexiva, propondo a partir do 
compartilhamento de saberes e experiências, a pesquisa e a investigação em educação, não se faz diferente.

O professor, autor e pesquisador Augusto Triviños, que é uma das referências metodológicas desta pesquisa, reforça o pensamento que a entrevista semiestruturada possui essa característica de possuir uma ampla possibilidade de interrogações, mas sem necessariamente sair do foco ou da linha de concepções.Com base nessa perspectiva de entrevista, semiestruturada, saliento que haverá um roteiro de perguntas fundamentais que irão sulear essa pesquisa, roteiro que contará com todas as informações que possuo até o momento, junto com todas as bases teóricas e as referências bibliográficas que fazem parte desta pesquisa.

É útil esclarecer, para evitar qualquer erro, que essas perguntas fundamentais constituem, em parte, a entrevista semi-estruturada, no enfoque qualitativo, não nasceram a priori. Elas são resultados não só da teoria que alimenta a ação do investigador, mas também de toda a informação que ele já recolheu sobre o fenômeno social que interessa, não sendo menos importantes seus contatos, inclusive, realizados na escolha das pessoas que serão entrevistadas. (TRIVIÑOS, 1987, p.146)

Pensando exatamente nesse viés que constrói uma responsabilidade social na pesquisa, para análise dos dados e das informações recolhidas junto dos sujeitos entrevistados nessa pesquisa, a priori utilizarei a concepção de Norman Fairclough, que a partir da Análise Crítica de Discurso (ACD), entende que o discurso está totalmente ligado a dominação das pessoas de determinada sociedade, assim como está para transformação de determinada realidade, já que o discurso é constituidor de determinadas realidades junto a lógica que está instaurada.

As ideologias construídas nas convenções podem ser mais ou menos naturalizadas e automatizadas, e as pessoas podem achar difícil compreender que suas práticas normais não poderiam ter investimentos ideológicos específicos. Mesmo quando nossa prática pode ser interpretada como de resistência, contribuindo para a mudança ideológica, não estamos necessariamente conscientes dos detalhes de sua significação ideológica. Essa é uma razão para se defender uma modalidade de educação linguística que enfatize a consciência crítica dos processos ideológicos no discurso, para que as pessoas possam tornar-se mais conscientes de sua própria prática e mais críticos dos discursos investidos ideologicamente a que são submetidas (ver Clark et al., 1998; Fairclough, 1992 - a). (FAIRCLOGH, 2011, p.120)

Nessa perspectiva contra hegemônica, Fairclough nos traz uma potencialidade de Análise de Discurso com a possibilidade de "inverter o jogo", entendendo que a mudança social passa por esse contraponto, percebendo que há uma ideologia que trabalha na manutenção do status quo, porém, há possibilidades de transformação. O que vem a calhar 
nessa investigação, que almeja caminha pelo viés da educação popular que é totalmente "encharcada" de criticidade e de potencialidades transformativas.

\section{Desenvolvimento}

É imprescindível situarmos teoricamente a EP no contexto histórico da América Latina e do Brasil, mas também, nos cabe a incumbência de expor o seu compromisso com a humanização e a emancipação dos homens e mulheres, ligadas ao trabalho, com suas produções culturais e sociais, e por isso, se posiciona em contrariedade com o "mercado de trabalho". A EP deve se localizar em contraponto ao capital.

No exercício de fazer um movimento em direção à História da Educação Brasileira, pode-se perceber que a Educação Popular (Brandão, 2002), a Educação do Campo (Caldart et alii, 2004), a Pedagogia do Oprimido ou a Educação Como Prática da Liberdade (Freire, 1987) e a Pedagogia Histórico-Crítica (Saviani) possuem um mesmo direcionamento: colocar a educação na perspectiva da emancipação humana; por isso mesmo, na relação com a totalidade social o compromisso dessas proposições educativas é com o trabalho e não com o capital (PALUDO, p.64)

Nesse sentido, os educadores e educadoras populares, se constituem como "intelectuais orgânicos", pela concepção gramsciana, onde o intelectual é aquele ou aquela que possui um compromisso com as camadas populares, com sua organização e com sua atuação política, fazendo de sua metodologia uma prática de transformação permanente, e assim, permitindo que a educação seja uma possibilidade de transformar a sociedade. Desse modo, Marco Raúl Mejía J. nos salienta acerca dessa concepção da EP:

En ese sentido, permitan dar um marco a esta presentación, em la cual, em um primer momento, plantearé que la educación popular es hoy uma propuesta educativa com um acumulado proprio, en que la saca de la acción intencionada em grupos sociales populares para convertirla em uma actuación intencionadamente política en la sociedade para transformar y proponer alternativas educativas e sociales desde los interesses de los grupos populares, evitando caer em el utopismo educativo y pedagógico que cree que solo cambiando su educación se transforma la sociedade y hace consciencia de que si no cambia la educación, será imposible transformar la sociedad. (MEJÍA J., p.369)

Do mesmo modo em que a EP traça uma perspectiva de resistência ao capital, ela também nos elucida acerca de nossa identidade, que por parte da colonização, deve ser descolonizada, afirmando que os países do Sul devem buscar em suas experiências uma constituição epistemológica. Por mais que tenhamos sido colocados como "periferia" e “colônia" pelos países do Norte e pelo modo de produção, temos que buscar em nossas particularidades culturais, sociais e políticas, a força para que venhamos a deixar de ser 
marginalizado. Aliado a essa ideia de que a EP deve desenvolver um papel contra hegemônico na cidade, onde o "arquiteto" é o capital, também nos interessa refletir a minha e a nossas práxis no Paidéia como uma Epistemologia do Sul, buscando em nós, as condições necessárias para a transformação de nossas vidas (Ser Mais) e a transformação do que está ao nosso redor. Para isso, precisamos nos entender não como residuais, ou como irracionais e primitivos, mas possuidores de envergadura ontológica, epistemológica e gnosiológica.

Desde o século XVIII, sobretudo com o iluminismo, no eurocentrismo foi-se afirmando a mitológica ideia de que a Europa era preexistente a esse padrão de poder, que já era antes um centro mundial de capitalismo que colonizou o resto do mundo, elaborando por sua conta, a partir do seio da modernidade e da racionalidade. E que nessa qualidade, a Europa e os europeus, eram o momento e o nível mais avançados no caminho linear, unidirecional e contínuo da espécie. Consolidou-se assim, juntamente com essa ideia, outros núcleos principais da colonialidade/modernidade eurocêntrica: uma concepção de humanidade segundo a qual a população do mundo se diferenciava em inferiores e superiores, irracionais e racionais, primitivos e civilizados, tradicionais e modernos. (QUIJANO, p.86)

Nesse processo ideológico europeu, de colocar a Europa como superior, centralizando e norteando o mesmo continente, a inferiorização dos demais continentes sofre um acréscimo com o processo de industrialização que coisificará os homens e mulheres, transformando-os em mão-de-obra, e nesse processo as mercadorias recebem um valor incomensurável.

A Europa nunca foi o centro da história mundial até finais do século XVIII (digamos, até o século XIX, apenas há dois séculos). Passará a ser o centro em consequência da revolução industrial. (DUSSEL, p.344)

A Educação Popular nos demonstra que há alternativas ao modo de produção existente, e por isso, em nossas epistemologias, experiências e teorias de resistência, cabe mapearmos também as experiências "rebeldes" em educação (rebeldes ao modo de produção capitalista) que estão presentes na América Latina, que nos ajudarão a potencializar a minha e as nossas práticas como educadores e educadoras, como pedagogia de resistência e como educação anticapitalista. Uma das experiências de educação anticapitalista que poderá nos alertar sobre as possibilidades de transformação de nossas vidas e do mundo em que vivemos, destacamos a educação zapatista, desenvolvida em Chiapas no México, desenvolvida pelo EZLN (Exército Zapatista de Libertação Nacional), que através da luta, da militância e da autonomia, constroem uma outra educação.

Podemos, portanto, observar que, de um modo geral, o Sistema Educativo Rebelde Autônomo Zapatista de Libertação Nacional tem importância estratégica na 
condução da luta e na construção da autonomia. A escola zapatista é engajada na luta e na garantia de direitos indígenas e camponeses através da conscientização popular e na construção de novas relações sociais. Ao mesmo tempo que se "manda obedecendo", como acatamento crítico às decisões coletivas, na educação se estabeleceu a condição "ensinando se aprende, aprendendo se ensina". (MORETTI, p.442)

O educador Miguel Arroyo nos alerta sobre necessidade emergente de construirmos uma outra educação, tendo em vista que a sociedade latino-americana, constituída na sua maior parte por uma população que vive e sobrevive reivindicando seus direitos para assim existir, necessita de uma educação que se encontre com as suas lutas, suas indagações para essa lógica que se coloca como inquestionável e suas afirmações para essa mesma lógica que lhes nega as condições basilares para o viver com dignidade.

\begin{abstract}
Em nossas sociedades latino-americanas são os grupos sociais que se fazem presentes em ações afirmativas nos campos, nas florestas, nas cidades, questionando as políticas públicas, resistindo à segregação, exigindo direitos. Inclusive o direito à escola, à universidade. São os coletivos sociais, de gênero, etnia, raça, camponeses, quilombolas, trabalhadores empobrecidos que se afirmam sujeitos de direitos. Outros Sujeitos. São seus filhos e suas filhas que se fazem presentes nas escolas públicas e que exigem o acesso às universidades. São os outros educandos. (ARROYO, p.09)
\end{abstract}

Há um auspício sobre a juventude, um anúncio de morte e violência contra aquelas e aqueles sujeitos jovens. Há um crescimento nos homicídios contra jovens. E é o que me e nos faz refletir quanto a educação que está posta, e ao mesmo tempo, refletir sobre a importância da EP nesse processo de constituição dessas trabalhadoras e desses trabalhadores da cidade e que fazem parte do Paidéia.

Nos últimos anos, segundo o Centro Brasileiro de Estudos Latino-Americanos, com base no Sistema de Informações de Mortalidade (SIM) do Ministério da Saúde, o número de homicídios contra jovens cresceu $346 \%$ entre 1980 e 2010, sendo a principal causa ada morte de jovens de até 19 anos no Brasil, segundo a fonte. A pesquisa também indica o crescimento, no país, da morte de crianças e jovens no trânsito, sendo que, entre 2000 e 2008, os números se estabilizaram e voltaram a crescer novamente a partir desse ano: "O principal motivo foi o aumento das mortes envolvendo motociclistas: 376,3\% entre 2000 e 2010”. Diante de fatos como esses, não há como desconsiderar que existe, de certo modo, um processo de anúncio de morte do futuro na medida em que se destroem - no presente- os sujeitos que o estabeleceriam. (CHAIGAR, p.296)

O sociólogo brasileiro Juarez Dayrell, professor da Universidade Federal de Minas Gerais, que possui uma grande experiência na pesquisa com os jovens e com juventude, nos elucida sobre as questões das produções culturais e sociais das juventudes, ao mesmo tempo em que, nos faz compreender que esse ou essa jovem, possui a capacidade de em sua 
singularidade, que diz respeitosa ao seu pensar sobre o mundo, suas representações sociais sobre o mundo, resultado de suas curiosidades epistemológicas, ou em outras palavras, elas e eles "tem o que dizer".

Para efeito desta análise, assumi a posição de Charlot (2000, p.33 e 51) para quem o sujeito é um ser humano aberto à mundo que possui uma historicidade; é portador de desejos, e é movido por eles, além de estar em relação com os outros seres humanos, eles também sujeitos. Ao mesmo tempo, o sujeito é um ser social, com uma determinada origem familiar, que ocupa um determinado lugar social e se encontra inserido em relações sociais. Finalmente, o sujeito é um ser singular, que tem uma história, que interpreta o mundo e dá-lhe sentido, assim como dá sentido à posição que ocupa nele, ás suas relações com os outros, à sua própria história e à sua singularidade. Para o autor o sujeito é ativo, age no e sobre o mundo, e nessa ação se produz e, é produzido no conjunto das relações sociais das quais se insere. (DAYRELL, 2003, p. 42-43).

Segundo Dayrell, é imprescindível que, no trabalho ou na pesquisa com os jovens, sejam meninas ou sejam meninos, compreendamos que os mesmos são pessoas que pensam e refletem sobre o mundo em que estão, interveem através de várias atividades, sejam elas culturais, políticas, sociais ou espirituais, possuidores de sentimentos, anseios, dúvidas e da necessidade de transformar o mundo e a suas vidas.

Uma das mais arraigadas é a juventude vista na sua condição de transitoriedade, onde o jovem é um "vir a ser", tendo, no futuro, na passagem para a vida adulta, o sentido das suas ações no presente. Sob essa ótica, há uma tendência de encarar a juventude na sua negatividade, como o que ainda não se chegou a ser (SALEM,1986), negando o presente vivido. Essa concepção está muito presente na escola: em nome do "vir a ser" do aluno, traduzido no diploma e nos possíveis projetos de futuro, tende a negar o presente vivido dos jovens como espaço válido de formação, bem como as questões existenciais que eles expõem, as quais são bem mais amplas do que apenas o futuro. Quando imbuídos por esta concepção, os projetos educativos perdem a oportunidade de dialogarem com as demandas e necessidades reais do jovem, distanciando-se dos seus interesses do presente, diminuindo as possibilidades de um envolvimento efetivo nas suas propostas educativas. (DAYRELL; GOMES, 2009 p.1-2).

Nessa complexa discussão, o mesmo geógrafo nos demonstra a potência da Cidade para essa sociedade urbana. Essa mesma Cidade que de certo modo é anterior à industrialização, porém, temos que entender o seu papel antes e o seu papel hoje.

A industrialização fornece o ponto de partida da reflexão sobre nossa época. Ora, a Cidade preexiste à industrialização. Esta é uma observação em si mesma banal, mas cujas implicações não foram inteiramente formuladas. As criações urbanas mais eminentes, as obras mais "belas" da vida urbana ("belas", como geralmente se diz, porque são antes obras do que produtos) datam de épocas anteriores à industrialização. Houve a cidade oriental (ligada ao modo de produção asiático), a cidade arcaica (grega ou romana, ligada à posse de escravos), depois a cidade medieval (numa situação complexa: inserida em relações feudais, mas em luta 
contra a feudalidade da terra). A cidade oriental e arcaica foi essencialmente política: a cidade medieval, sem perder o caráter político, foi principalmente comercial, artesanal, bancária. Ela integrou os mercadores outrora quase nômades, relegados para fora da cidade. (LEFEBVRE, p.03)

É de grande valia entendermos o caráter da Cidade nos diferentes processos históricos e nas diferentes sociedades, como apontou Lefebvre ao discorrer sobre as variadas cidades que existiram e que deram uma base a atual Cidade, que é o resultado da sociedade capitalista, que se desenvolveu após os processos de industrialização, potencializado pela globalização. . A cidade, ao olharmos de perto, propõe para nós o encontro da realidade social que se encontra presa nas relações do capitalismo, expondo toda a feiura das mazelas que são cotidianamente produzidas.

\begin{abstract}
A cidade não é apenas a organização funcional do espaço, suas ruas e edificações, seus bairros, pessoas carregando sonhos, isoladas na multidão, em um deserto de prédios, que aboliu o horizonte e apagou as estrelas. A cidade é a expressão das relações sociais de produção capitalista, sua materialização política e espacial que está na base da produção e reprodução do capital. A cidade é a forma reificada dessas relações, mas também do amadurecimento das contradições que lhes são próprias. É a unidade de contrários, não apenas pelas profundas desigualdades, mas pela dinâmica de ordem e da explosão. As contradições, na maioria das vezes, explodem cotidianamente, invisíveis. Bairros e pessoas pobres, assaltos, lixo, doenças, engarrafamentos, drogas, violência, exploração, mercado de coisas e de corpos transformados em coisas. As contradições surgem como grafites que insistem em pintar cores e beleza a cidade cinza e feia. Estão lá, pulsando, nas veias que correm sob a pele urbana. (IASI, 2013, p. 41).
\end{abstract}

Na cidade hoje, para além das obstruções construídas pelas artimanhas do capital, também percebemos que o tempo também foi reduzido (como foi reduzido em todos os lugares em que o capitalismo se instaurou), e da mesma forma percebemos que a vida de homens e mulheres são desperdiçadas.

\title{
4. Considerações/Resultados
}

Desse modo, entendo que é possível a superação de todas as discrepâncias que o mesmo capitalismo vomita para o mundo, sabendo que, o desemprego é somente uma das problemáticas existentes. Desde que haja uma conscientização dos sujeitos, conscientização essa que emerge da prática, da opressão e das dificuldades impostas pelo capitalismo através do mercado de trabalho, pode-se construir e organizar alternativas reais para que a transformação seja colocada em prática. Como nos fala István Mészáros:

Ademais, o que é historicamente criado pelos seres humanos - mesmo que, em sua origem, sob a condição de antagonismos sociais estruturalmente engastados - pode 
ser também historicamente alterado e em última instância consignado ao passado. Mas a precondição necessária para o sucesso nesse respeito é o engajamento dos indivíduos na tarefa de superação dos antagonismos em questão por meio da instituição de uma ordem social radicalmente diferente e historicamente viável: o único modo concebível pelo qual os antagonismos estruturais profundamente enraizados podem ser suplantados. (MÉSZÁROS, 2007, p.39).

Aquilo que Mészáros sinaliza, é fundamental no que tange a postura das mulheres e dos homens, que cerceados pelas mais antagônicas situações-limites, enfrentam corajosamente a realidade de frente, realidade essa que de tão verticalmente desigual, impõe as mazelas, a miséria, a violência e a desesperança para milhares de jovens que estão começando a lançar-se ao mundo. Porém, há que se construir uma concepção de crítica, que consiga dar conta de nossa realidade, fazendo um contraponto a essa lógica que nos pede que sejamos e que continuemos subjugados pelo capitalismo.

A crítica arrancou as flores imaginárias dos grilhões, não para que o homem suporte grilhões desprovidos de fantasias ou consolo, mas para que se desvencilhe deles e a flor viva desabroche. (MARX, 2010, p.146)

É por isso, que a educação popular se configura como educação política, pois opta por aquelas pessoas que estão enclausuradas em projetos de silenciamento, desumanização e várias violências já citadas que constituem a concretude da vida das mesmas. Essa opção se dá pelo entendimento que dentro da realidade concreta dessas mulheres e homens, na luta cotidiana, para se fazer os enfrentamentos necessários e para que se conquiste a dignidade humana que lhes foi roubada, a formação política, a consciência crítica e a contestação é imprescindível.

É como homens que os oprimidos têm de lutar e não como "coisas". É precisamente porque reduzidos a quase "coisas", na relação de opressão em que estão, que se encontram destruídos. Para constituir-se é importante que ultrapassem o estado de quase "coisas". Não podem comparecer à luta como quase "coisas" para depois serem homens. É radical essa exigência. A ultrapassagem deste estado, em se destroem, para o de homens, em que se reconstroem, não é a posteriori. A luta por essa construção começa no auto reconhecimento de homens destruídos. (FREIRE, 2016, p.100).

A educação popular ao se comprometer com os processos de emancipação e de humanização dos sujeitos puxa para si essa tarefa de construção, que vai da constatação e do entendimento por parte das camadas populares de que são quase coisas até a humanização, movimento árduo, mas que em sua metodologia encontra a esperança necessária que faz caminhar até a efetivação e a ratificação da libertação em coletividade. 


\section{Referências.}

ARROYO, Miguel G. Outro Sujeitos, Outras Pedagogias. 2.ed. - Petrópolis, RJ: Vozes, 2014.

BRANDÃO, Carlos Rodrigues. A Pergunta a Várias Mãos: a experiência da partilha através da pesquisa na educação. São Paulo: Cortez, 2003.

CHAIGAR, Vânia Alves Martins. Aprendizagens e Itinerários Juvenis: cidade e cidadania sob o véu de narrativas e memórias. In: PORTUGAL, Jussara Fraga; CHAIGAR, Vânia Alves Martins (Orgs.). Educação Geográfica: memórias, histórias de vida e narrativas docentes. Salvador: EDUFBA, 2015, p. 295-318.

DAYRELL, Juarez. O jovem como sujeito social, 2000.

DAYRELL, Juarez Tarcísio; GOMES, Nilma Lino. A Juventude no Brasil. Observatório da juventude, 2009.

DUSSEL, Enrique. Filosofia da Libertação. São Paulo: Edições Loyola, 1977.

FAIRCLOUGH, Norman. Discurso e Mudança Social. Brasília: Editora Universidade de Brasília, 2011.

FREIRE, Paulo. Pedagogia do Oprimido. 60. ed. Rio de Janeiro: Paz e Terra, 2016.

IASI, Mauro Luis. A Rebelião, A Cidade e a Consciência. In: Cidades Rebeldes: passe livre e as manifestações que tomaram as ruas do Brasil. São Paulo: Boitempo: Carta Maior, 2013.

LEFEBVRE, Henri. O Direito à Cidade. 5.ed. São Paulo: Centauro, 2001.

MARX, Karl. Crítica da Filosofia do Direito de Hegel. 2.ed. São Paulo: Boitempo, 2010.

MEJÍA J., Marco Raúl. La Educación Popular: uma construcción colectiva desde el sur y desde abajo. In STRECK, Danilo R.; ESTEBAN, Maria Teresa (orgs.). Educação Popular: lugar de construção social e coletiva. Petrópolis, RJ: Vozes, 2013.

MÉSZÁROS, István. O Desafio e o Fardo do Tempo Histórico: o socialismo no século XXI. São Paulo: Boitempo, 2011.

MORETTI, Cheron Zanini. Subcomandante Insurgente Marcos: educação rebelde, autônoma e zapatista. In STRECK, Danilo R. (org). Fontes da Pedagogia latino-americana: uma antologia. Belo Horizonte: Autêntica Editora, 2010.

PALUDO, Conceição. Educação Popular e Educação no Campo: nexos e relações. In: STRECK, Danilo R.; ESTEBAN, Maria Teresa (Orgs.). Educação Popular: lugar de construção social e coletiva. Petrópolis, RJ: Vozes, 2013, p.64-76.

QUIJANO, Anibal. Colonialidade do Poder e Classificação Social. In SANTOS, Boaventura; MENESES, Maria Paula (orgs.). Epistemologias do Sul. São Paulo: Cortez, 2010, p.84 -130. 
RELACult - Revista Latino-Americana de Estudos em Cultura e Sociedade

Revista Latinoamericana de Estudios en Cultura y Sociedad | Latin American Journal of Studies in Culture and Society V. 04, ed. especial, fev., 2018, artigo n ${ }^{\circ} 748$ | relacult.claec.org | e-ISSN: 2525-7870

TRIVIÑOS, Augusto Nibaldo Silva. Introdução à Pesquisa em Ciência Sociais: a pesquisa qualitativa em educação. São Paulo: Atlas, 1987. 